\title{
OS DESNUDES MEMORIALÍSTICOS DOS HOMO-BIOS DE SILVIANO SANTIAGO E DE VIRGINIA WOOLF
}

\author{
Pedro Henrique Alves de Medeiros* \\ Edgar Cézar Nolasco ${ }^{* *}$
}

RESUMO: Este trabalho tem por objetivo realizar uma leitura comparatista, biográfica e fronteiriça entre as obras Mil rosas roubadas (2014), do escritor brasileiro Silviano Santiago, e Orlando: uma biografia (2017), da inglesa Virginia Woolf. Para isso, utilizaremos uma metodologia de caráter bibliográfico pautada na epistemologia crítica biográfica fronteiriça com o intuito de discutirmos as semelhanças e as diferenças homo-biográficas entre os autores e os livros citados ao passo que, simultaneamente, promoveremos desnudes de suas personae literárias, metafóricas e empíricas atravessadas pelos espaços (auto)biográficos que lhes concernem. Dentre os conceitos utilizados para o ensejo mencionado, valer-nos-emos da memória, aliados hospitaleiros, exterioridade, homo-biografia e amizade corroborados, dentre outros, pelos intelectuais Leonor Arfuch, Eneida Maria de Souza, Juliano Garcia Pessanha, Walter Mignolo, Jacques Derrida e Francisco Ortega. Portanto, respaldados pelo exposto, buscaremos delinear grafias comparatistas entre Silviano e Virginia no que concerne as suas existências outras enquanto escritores homossexuais que escre(vi)vem, ou escre(vi)veram, assentados em modus operandi e vivendi passíveis de os aproximarem não só no plano de suas semelhanças homobiográficas e literárias, mas, sobremaneira, das diferenças que os separam aproximando-os.

PALAVRAS-CHAVE: Crítica biográfica fronteiriça; Silviano Santiago; Virginia Woolf; Homobiografias; Desnudar.

Eu me senti - logo depois de ter trocado o primeiro olhar e as primeiras palavras terem sido ditas - diamante ou pepita de ouro na bateia da praça Sete. Caí nos seus olhos como cisco impelido por vento soprado do Oeste Mineiro. Levei tombo na surpresa. Confesso. Levantei, dei a volta por cima e escorri como mel pelos seus nervos óticos. Só reganhei figura humana quando bati finalmente à porta do coração. (SANTIAGO, 2014, p. 103, grifos nossos)

E, como todos os amores de Orlando tinham sido mulheres, em virtude da condenável morosidade do corpo humano em se adaptar às convenções, embora ela própria fosse mulher, era ainda de mulher que ela gostava, e se a consciência de ser do mesmo sexo do objetivo dessa preferência

\footnotetext{
* Mestrando em Estudos de Linguagens pela Universidade Federal do Mato Grosso do Sul (UFMS). Membro do Núcleo de Estudos Culturais Comparados (NECC) e Presidente da Comissão Organizadora dos Cadernos de Estudos Culturais . Bolsista Capes.

** Doutor em Literatura Comparada também pela Universidade Federal de Minas Gerais (UFMG). Professor da Universidade Federal de Mato Grosso do Sul (UFMS). Atualmente está desenvolvendo estágio de Pós-Doutorado no PACC na UFRJ. Membro do GT de Literatura Comparada da ANPOLL.
} 
tinha qualquer efeito era o de reavivar e aprofundar aqueles sentimentos que tivera quando homem. (WOOLF, 2017, p. 108)

É pelo alicerce da perspectiva metafórica de um nascimento surpreendido por saudades absurdas (PESSANHA, 2018) que Mil rosas roubadas (2014) e Orlando (2017) se lançam ao mundo, ainda que ressalvadas suas diferenças. Silviano, encoberto pelo manto fúnebre da morte do amigo-amado Ezequiel Neves (Zeca) e alicerçado pelo que entendemos, à luz de Jacques Derrida e de Francisco Ortega, por discurso do epitáfio (o ato de amar o amigo para além da vida e da morte) responsável por girar a chave ficcional que (des)arquiva suas memórias homo-biográficas da exterioridade narrando suas Mil rosas roubadas (2014): "Perco meu biógrafo. Ninguém me conheceu melhor que ele. Nascemos um para o outro aos dezesseis anos de idade, em Belo Horizonte, nos idos de 1952." (SANTIAGO, 2014, p. 07).

Já em Virginia, dentre outros aspectos, a falta se configura, essencialmente, pela não estabilidade e a não permanência de Orlando, à lá Vita Sackville-West (Vita) ${ }^{1}$, em suas relações amorosas, levando-o/a muitas vezes a sofrer pelas desilusões que o/a perpassam. Nesse sentido, para o narrador-biógrafo-anônimo de Orlando, o amor tem duas caras, uma branca e outra negra, que estão estreitamente unidas e ninguém consegue separá-las (WOOLF, 2017, p. 79). É justamente essa duplicidade do amor que fundamenta a escrita-vivência de Orlando pela abertura do arquivo-sensível-afetivo e trabalho com as memórias homobiográficas de Virginia, uma vez que a biografia-romanceada da autora inglesa foi, ao mesmo tempo, uma maneira de exorcizar seus sentimentos mais dolorosos por Vita diminuindo a obsessão extenuante para conservar seu amor (CURTIS, 2005, p. 187).

Isso posto, ao estabelecermos uma leitura comparatista-biográfica-fronteiriça entre as obras Mil rosas roubadas e Orlando, entrevemos a necessidade de não só nos deter comparativamente nesses corpos discursivo-literários, mas, sobretudo, desnudar homo-bios outros, de

\footnotetext{
${ }^{1}$ Vita Sackville-West (Vita) foi uma aristocrata inglesa do século XX a qual Virginia Woolf manteve um relacionamento amoroso-sexual e uma amizade para além da vida. A partir disso, deslindou-se a escrita da obra Orlando: uma biografia (1928) baseada na figura homo-biográfica e singular de Vita.
} 
Silviano e de Virginia, sujeitos dotados de memórias homo-biográficas. Para a articulação da crítica do bios, faz-se necessário o exercício de desnudar aqueles que herdamos, selecionamos e amamos a partir de nossas presenças, ausências e desejos. Roubamos as memórias homo-biográficas das exterioridades de Silviano, de Zeca, de Virginia, de Vita e, claro, de Orlando para pensar as nossas próprias memórias de pesquisadores-meninos-bomens-fronteiras homo-biográficos. Desnudamo-(n)os para falar; assim, no tanger aos espaços biográficos endossados nesse trabalho, evocamos algumas fotografias de Silviano (Figura 1), de Virginia (Figura 2) e de Vita (Figura 3):

Figura 1 -Silviano Santiago para o "Jornal da Biblioteca Pública do Paraná"

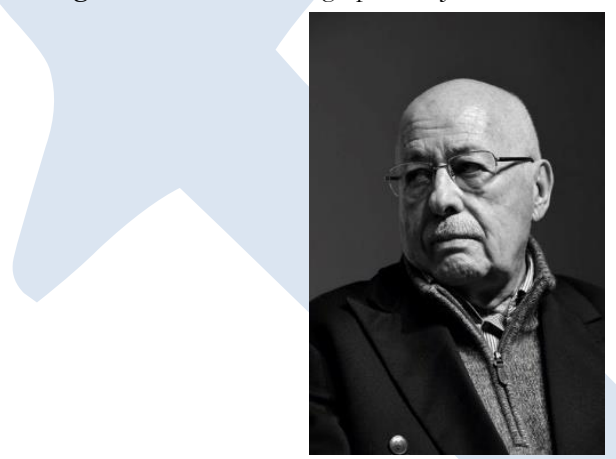

Fonte: http://www.bpp.pr.gov.br/Candido/Pagina/Um-Escritor-na-Biblioteca-Silviano-Santiago

Figura 2 - Virginia Woolf, fotografia reproduzida no texto "Virginia Woolf. A história íntima da inteligência" de Diogo Vaz Pinto publicado no "Jornal SOL - Sapo" de Portugal

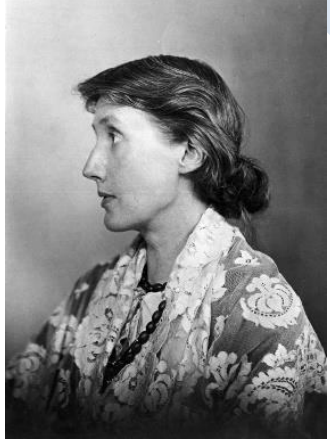

Fonte: https://sol.sapo.pt/artigo/565447/virginia-woolf-a-historia-intima-da-intelig-ncia 
Figura 3 - Vita Sackville-West, fotografia reproduzida no texto "Vita Sackville-West: British writer" de “The Editors of Encyclopaedia Britannica" (2020)

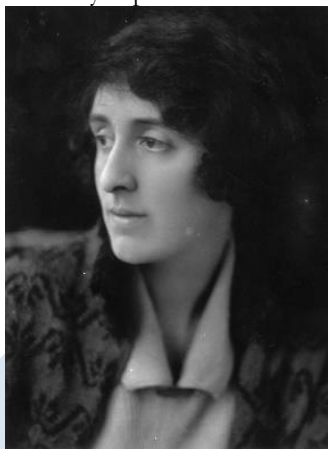

Fonte: https://www.britannica.com/biography/V-Sackville-West

Diante das fotografias reproduzidas/desnudadas acima (Figuras 1, 2 e 3) e por vias da consciência do bios alocada em um espaço (auto)biográfico (ARFUCH, 2010), o olhar que lançamos para as obras Mil rosas roubadas e Orlando, bem como para os seus respectivos escritores, é fomentado pelas reflexões que concernem à memória enquanto atividade de reelaboração em que se reconhecem os ganhos e a perdas, os jogos de equívocos, as armadilhas, as máscaras, os desdobramentos, as perturbações de identidade etc. (ARFUCH, 2010, p. 56). Pensar a memória, por consequência, implica falar do esquecimento, da presença, da ausência e dos dados que fundamentam o material cinzento e contraditório do passado (SOUZA, 2012, p. 28).

O esquecimento, ao se voltar para o espaço da ausência, impulsiona o exercício de reelaboração da experiência no presente (SOUZA, 2012, p. 28). A memória, portanto, ficcionaliza lembranças e esquecimentos de experiências daqueles que escre(vi)vem, dado que entre o acontecimento e sua narração há um espaço em profundidade (EVARISTO, 2017) onde explode a invenção. Assim, os bastidores de recriação dos eventos, dos lugares e das pessoas são como acontecimentos ficcionalizados ao receberam os toques pessoais-sensíveis dos escritores integrando-se aos imaginários de suas respectivas épocas (SOUZA, 2011), Virginia na Inglaterra do século XX e Silviano no Brasil nos dias atuais. Escrever é perseguir uma escrevivência (EVARISTO, 2017, 10). Diante disso, Orlando e Mil rosas roubadas, acerca da memória, explicitam: 
A Memória é uma costureira e, não bastasse isso, das cheias de capricho. A Memória conduz sua agulha para fora e para dentro, para cima e para baixo, para cá e para lá. Não sabemos o que vem em seguida nem o que virá depois. Assim, o ato mais corriqueiro do mundo, como sentar-se a uma mesa e puxar para perto o suporte com o tinteiro e a pena, pode agitar milhares de fragmentos discrepantes, desconectados, ora acesos, ora apagados, subindo e flutuando e descendo e oscilando, tal como, surpreendidas no varal por um pé de vento, as roupas de baixo de uma família numerosa. (WOOLF, 2017, p. 53)

Não existe melhor apoio ou muleta para os devaneios da memória admirativa que a imaginação. Devaneio e imaginação são amigos e mijar juntos. Atenção a eles. Aliados, dão de dez em você que só serve para embotar os passos do devaneio. Talvez por já me sentir bandeando para o lado da imaginação, continuei a alertar a razão, embora, na verdade, estivesse a alertar a mim sobre a necessidade do futuro desvio na condução do relato. (SANTIAGO, 2014, p. 172-173)

À vista disso, em ambas as obras supracitadas, há a perspectiva da memória do viés da recriação no presente preenchida pela invenção dos autores deslindando a (con)fusão entre vida e escrita ou escrita e vivência (EVARISTO, 2017, p. 12): elementos de contaminação altamente produtivos para as literaturas discutidas. Em Orlando, esse fato se desvela essencialmente no terceiro capítulo (o qual Orlando vai a Constantinopla como embaixador extraordinário) em que faltam arquivos passíveis de consulta para a construção narrativa e, por isso, conforme Silviano Santiago expõe em "Entre a flexibilidade e o rigor" (2017), na posição de crítico, a falta do documento é compensada pela especulação dos antepassados de Vita (SANTIAGO, 2017, p. 274). O capítulo III de Orlando se inicia do seguinte modo: "É realmente uma grande desgraça [...] que, nessa fase da carreira de Orlando, quando desempenhou um papel muito importante na vida pública [...] tenhamos pouquíssima informação em que confiar." (WOOLF, 2017, p. 81). No lugar em que se falta referencial, explode-se, portanto, o manejo inventivo e fabular de Virginia Woolf.

Além disso, outro elemento que corrobora a reinvenção do passado é a construção do/da personagem Orlando, pois, ainda que o referencial dele/a seja Vita, ele/ela é, essencialmente, a recriação da amante de Virginia no presente cindido/a por todas as presenças e ausências que o exercício da memória impõe. A matéria da ficção de Virginia, ainda que 
pareça ter sido tirada de sua vida, e muitas partes realmente foram, são sutilmente transmutadas durante o processo criativo (SCHULKIND, 1986, p. 30) de abertura do arquivo e do trabalho com a memória. Orlando é não sendo Vita, pois, ao recuperá-la, Virginia se perde em sua criação abandonando a imagem ilusória de uma intocável subjetividade de sua paixão homo-biográfica:

Não é por acaso que Uma biografia seja o subtítulo de Orlando. O gênero biográfico e autobiográfico - ainda que vazado na forma romance que lhes vem sendo proposta como semelhante e paralela pelos autores ingleses desde o século XVIII - possibilita que a vida amorosa do/da protagonista e sua vida política e pública se embaralhem na fabulação ficcional, criando ininterruptas zonas de sobreposição de um plano sobre o outro. Os jogos de sobreimpressão para usar a linguagem da montagem cinematográfica - dos corpos serão constantemente ativados pela escrita contraditoriamente convencional de que se vale o Narrador idealizado por Virginia para conduzir a trama romanesca. (SANTIAGO, 2017, p. 269)

No que convém às Mil rosas roubadas de Silviano, a questão da memória é ainda mais latente, haja vista que a cerne da narrativa é justamente a tentativa do narrador-sobrevivente de biografar o amigo-amado-morto Zeca. Através dessa tentativa de biografia, Silviano, o qual compreendemos como a metáfora do próprio narrador, evoca uma série de questões não só sobre as escritas de si e do outro perpassadas pelas memórias do escritor mineiro com Ezequiel Neves. Silviano delineia em seu texto-romance-biografia as angústias e os percalços que o evento de narrar uma vida implica, como resvalar em subjetivismos, em recalques, em desvios dos fatos, em recriações, em narcisismos etc.

Para ele, "[...] somos todos lacunares quando se trata de narrar as várias facetas de uma vida." (SANTIAGO, 2014, p. 221), há que se desconfiar de antemão do que se sabe (SANTIAGO, 2014, p. 264), inclusive e essencialmente, da memória que blefa aparecendodesaparecendo de maneira constante. O mineiro leva o gesto de recriação a partir da premissa memorialística à última potência em Mil rosas roubadas, sua persona narradora se embebe do escritor-ensaísta-crítico literário delineando não só suas angústias na posição de então (auto)biógrafo, mas enquanto alguém que escre(vi)ve com base em uma consciência crítica de que lembrar implica esquecer e reinventar: "Preencho o duplo vazio, da memória, e do esquecimento, com palavras que não são as legítimas dele mas que talvez pudessem 
ter sido as dele [...]" (SANTIAGO, 2014, p. 77). Silviano se torna refém da memória (SOUZA, 2011) “distorcida" resvalando a tessitura biográfica em autobiográfica permeada por invenções e interpretações de ordem pessoais, ainda que tente ser objetivo:

O fio das palavras objetivas perde direção e significado e é coagulado em dor e suplício na mancha negra escrita no branco do papel, onde se dá o conflito da biografia com a plena subjetividade, assim como, no filme $\grave{A}$ noite sonhamos, o borrifo do sangue tuberculoso de Chopin no teclado alvinegro do piano propõe um fim singular ao concerto e à vida do pianista. [...] Tudo é subjetivo neste relato. (SANTIAGO, 2014, p. 144-145, grifos nossos)

Tudo é subjetivo, e sensível, nesse relato. Na esteira do exposto sobre/a partir de Silviano e de Virginia, entrevemos que o excerto acima do romance Mil rosas roubadas não se sustenta só para aquele que o profere, isso é, para Silvino, mas, proficuamente, possui validação crítica-metafórica-biográfica a ambos os autores e suas respectivas escritas-vivências sobre/a partir de Zeca, Vita e Orlando. Para Eneida, à luz de Pedro Nava, em Tempo de pós-crítica (2012), o memorialista há de se conscientizar da impossibilidade de formatação de uma paisagem em sua completude pelo fato de existirem peças faltantes e por essas deixarem buracos no céu, hiatos nas águas, sombras nos sorrisos, furos na silhuetas interrompidas e nos peitos que se abrem no vácuo como vitrais furados (NAVA apud SOUZA, 2012, p. 26). É nesses espaços lacunares que Silviano e Virginia manejam suas escritas-vivências homo-biográficas as potencializando por meio dos exercícios inventivos e reconstitutivos da ficção.

Nesse cenário, como explicita Jeanne Schulkind, organizadora do livro Momentos de vida (1986) de Virginia Woolf, o julgamento da obra literária não requer de maneira nenhuma o conhecimento de suas raízes autobiográficas (SCHULKIND, 1986, p. 28). Todavia, o conhecimento dessas só faz enriquecer a leitura possibilitando as mesmas densidades de associações que a memória dá ao momento presente (SCHULKIND, 1986, p. 28). Com isso, ler e estabelecer relações de semelhanças e diferenças entre Mil rosas roubadas e Orlando tendo como eixo de comparação as escritas-vivências de seus autores incide apenas como uma das maneiras de leitura e articulação. Optamos por esse caminho crítico devido ao respaldo crítico-fronteiriço-comparativo-biográfico que nos assentamos para teorizar. Em 
linhas gerais, compactuamos com a ironia exposta pelo narrador-biógrafo-anônimo de $\mathrm{Or}$ lando: "[...] cada segredo da alma de um escritor, cada experiência de sua vida, cada atributo [...] está todo inscrito em sua obra; apesar disso, ainda convocamos críticos para comentarlhe a obra e biógrafos para contar-lhe a vida." (WOOLF, 2017, p. 138).

Ainda para o narrador de Orlando, a sociedade é tudo e a sociedade é nada e só os poetas e romancistas conseguem lidar com seus monstros (WOOLF, 2017, p. 128). Nesse viés, entendemos que toda biografia e/ou relato de experiência, como Mil rosas roubadas e Orlando delineiam, são, em certa medida, algo coletivo, pois corroboram a expressão de uma época, de um grupo, de uma geração, de uma classe, de uma narrativa comum de identidade (ARFUCH, 2010, p. 100). Conforme Leonor Arfuch, em O espaço biográfico (2010), é essa a qualidade coletiva, como rastro impresso nas singularidades o que tornam relevantes as narrativas de vida, sobretudo, do nosso ponto de vista, das (sobre)vidas outras, homo-biográficas, como as de Silviano Santiago e de Virginia Woolf. Nessa visada das memórias homo-biográficas rechaçadas e desautorizadas pelo discurso patriarcal heteronormativo vigente, endossamos que:

As memórias subterrâneas, ao emergirem em espaços delineados pelo poder da escrita, rasuram a cena dos grandes feitos e permitem a composição de outras histórias nascidas [...] da experiência da periferia e da marginalidade. O movimento que caracteriza o afloramento das memórias confinadas ao silêncio instiga a escuta das vozes que emanam do corpo dos espoliados, dos indivíduos acossados pela dor da pobre [exclusão] extrema. (FONSECA, 2017, p. 191192)

Diferente do lugar de onde a citação supracitada fala, da periferia e da marginalidade socioculturais com base em Becos da memória de Conceição Evaristo, assentamo-nos em tais perspectivas de exclusão para pensar as escritas-vivências/memórias/arquivos de Silviano Santiago e de Virginia Woolf com base em suas homo-biografias da exterioridade patriarcal-heterossexista. É a partir desse lócus epistemológico de periferia e de exclusão que situamos tanto os autores que amamos, pelo crivo de uma feriada similar de um texto amizade (PESSANHA, 2018, p. 16), quanto as nossas próprias existências de intelectuais homossexuais e sul-fronteiriços. É na canibalização das narrativas, memórias e escritas- 
vivências dos nossos escritores Silviano e Virginia que buscamos nos contrapor às imagens e aos discursos sexualmente controladores e cristalizados, sobretudo, no conservadorismo latente brasileiro perpassado por um momento em que grassam as intolerâncias, os discursos de ódio e a violência aos sujeitos das exterioridades, não apenas os sexuais como nós, mas também, os raciais, os étnicos etc.

Desse modo, nosso fazer fronteiriço-comparatista-biográfico tangível aos nossos homo-bios (Silviano/Virginia/Pedro) se explicita baseado em uma exterioridade aberta e em constante sangramento, uma vez que, homo-biograficamente, sentimos e rivalizamos a fronteira em nossos corpos de homens-meninos-fronteiras atravessados pelas histórias outras que canibalizamos e tomamos para nós, como as de Mil rosas roubadas e as de Orlando. À semelhança de Silviano e Virginia, desnudamo-nos enquanto críticos homossexuais propondo reflexões comparatistas e aquilatando narrativas outras as quais julgamos necessárias de serem discutidas na academia: formas de sociabilidade políticas (ORTEGA, 1999) outras entre dois homens amigos-amantes, entre duas mulheres lésbicas/bissexuais também amantes e, sobretudo, pela figura de Orlando que não é nem natural, homossexual, andrógino ou gay, mas queer(SANTIAGO, 2017, p. 268). Afinal, contamos histórias porque as vidas humanas precisam e merecem ser contadas (RICOEUER apud ARFUCH, 2010, p. 111), sobretudo, aquelas que foram relegadas à inexistência da exterioridade.

Dadas essas aproximações metafóricas crivadas pela sexualidade, entendemos que, transferencialmente, aproximamo-nos e distanciamo-nos, simultaneamente, de Silviano e Virginia e dos seus projetos homo-bio-ficcionais de maneira simbiótica e canibalizadora (PESSANHA, 2018). Falamos de nós e nos escre(vi)vemos através deles. Executamos o exercício (des)arquiviolítico a partir dos arquivos homo-biográficos de Silviano e de Virginia que se abrem a partir da nossa inserção enquanto críticos também homossexuais nos estabelecendo enquanto aliados hospitaleiros de Silviano e de Virginia, dado que aferimos ressonâncias aos seus espectros por intermédio de nossas feridas homo-biográficas similares. Para respaldar esse processo de metaforização intercorporal, Juliano Garcia Pessanha assente: 
Aliado hospitaleiro é aquele que permite ser devorado, canibalizado e criado pelo outro polo no duo bipolar. $\mathrm{O}$ aliado hospitaleiro permite a confusão no tráfego de gestos e todo tipo de mergulho extático na área surreal da intercorporeidade. [...] Nos duetos originários, o 'roubo' é consentido, pois o outro é, simultaneamente, outro é minha própria obra, isto é, eu mesmo. (PESSANHA, 2018, p. 71, grifos nossos)

Criamos, portanto, nossas formulações epistêmicas acerca das obras Mil rosas roubadas e Orlando na mesma medida em que somos criados por elas (PESSANHA, 2018). Sendo assim, perpassados por esses contextos de modos de vidas outros, homo-biográficos/ queer, de Silviano, Zeca, Virginia, Vita e Orlando, fazemos questão de (de)marcar, por uma razão política de existência, a partir de onde falamos enquanto divíduos sexualmente marginalizados e subalternizados pela hegemonia heternormativa e compulsória da interioridade. Buscamos, nessa esfera, repensar as questões de dentro e fora no que tange às nossas existências homo-biográficas:

Mas se a metafísica da presença pensou apenas o Dentro, devemos, agora, a começar a pensar o Fora. E devemos fazê-lo não porque isso seja apenas uma novidade ou um pensamento diferente no mercado das ideias. Não: pensar o Fora [...] [é] operar uma mutação na nossa maneira de existir. Somos, hoje, eticamente forçados a pensar diferente, porque estamos, pela primeira vez, numa situação capaz de perceber a violência e a agressão que dormitavam no pensamento metafísico. (PESSANHA apud NOLASCO, 2015, p. 48)

Com base na passagem de Pessanha, reiteramos a necessidade de pensar o Fora enquanto aquilo que foi desconsiderado pela história moderna, hegemônica, colonial e heterossexual europeia/norte-americana, isso é, a exterioridade criada pela interioridade. O discurso crítico academicista e disciplinar é exemplar em repetir teorias/narrativas itinerantes que grassam dos centros mundiais modernos para as bordas do planeta sem considerar as sensibilidades locais dos seus hospedeiros e, tampouco, seus loci geo-históricos.

Narrativas de homens brancos, burgueses e heterossexuais se sustentam como temática universal no cerne dos estudos de literatura subsidiadas pela falácia de que essas histórias dão conta de narrar todas as histórias. Isso posto, indagamo-nos: como essas narrativas ditas universais podem dar conta das diversalidades pluritópicas e pluriversais dos modos de vidas e existências de Silviano, Zeca, Virginia, Vita e, sobretudo, de Orlando? Esse 
discurso supostamente universal não se sustenta para todos, ele rechaça, expurga e marginaliza pelo crivo da diferença, no caso dessa leitura, essencialmente sexual.

É sob a égide desse contexto colonial-moderno que tomamos Mil rosas roubadas e Orlando na direção de literaturas homo-biográficas da exterioridade que se escre(vi)vem através das aberturas dos arquivos de modos de vidas outras assentados em sociabilidades extrínsecas à lógica dita universal homogênea e que performatizam comportamentos que, a priori, não lhes seriam permitidos em detrimento a um princípio de masculinidade/feminilidade e/ou sociabilidade estabelecidos pela interioridade patriarcal. Nossas histórias locais, sensibilidades e opções homo-bio-epistêmicas são endossadas por uma lógica não considerada pela colonialidade. Sociabilidades homoafetivas/homo-biográficas são amplamente rechaçadas e relegadas ao esquecimento por não serviram à lógica da interioridade que dissipa aquilo que destoa da norma. Fomos/somos expurgados para as margens, para as bordas e para a exterioridade. No plano das questões que conclamamos de homo-biográficas, Francisco Ortega, em Genealogias da amizade (2002), explicita:

A modernidade prolongou essa atitude de total abominação e condenação universal da homossexualidade, a qual se torna um problema médico e sociopolítico no século XIX, de tal maneira que até boje é quase impossivel mostrar afeto nas relações de amizade, especialmente considerado homoerótico. 'Para dizer 'te amo' a um amigo ou amiga é necessário atravessar até no próprio corpo inúmeras grades históricas, uma floresta imensa de proibições e distinções, códigos, cenários, posições". (DERRIDA apud ORTEGA, 2002, p. 91, grifos nossos)

À guisa desse intento, entrevemos que o romance Mil rosas roubadas se insere na contracorrente do exposto pela modernidade colonial (interioridade) que primou pela exclusão da afetividade entre homens em detrimento a um padrão de masculinidade patriarcal e excludente. Desde os passos iniciais do (des)arquivamento das memórias de Silviano, tornadas narrativas, já se visualiza a declaração que é repetida mais de uma vez no texto "Nascemos um para o outro aos dezesseis anos de idade [...]” (SANTIAGO, 2014, p. 07). Dentro da lógica colonial que dissipa as sensibilidades outras, esse tipo de afetividade sensível entre homens é enxergado como impróprio e até pecaminoso - tendo em vista que o pensamento moderno-colonial é essencialmente cristão. Silviano, ao escre(vi)ver a partir de 
uma exterioridade sensível, biolocal e epistêmica, narra sua história de amizade/amor com seu amigo-amado político e quase biógrafo.

Podemos, portanto, ler a relação de Silviano com Zeca em Mil rosas roubadas sob o crivo metafórico da liberdade de uma borboleta-azul ${ }^{2}$ que voa para além da floresta imensa de proibições e distinções, códigos, cenários e posições. A imagem da borboleta-azul é um ponto fundamental na (boa) amizade política/relacionamento entre os rapazes uma vez que explicita um dos principais momentos de afetividade, pois, ao Zeca demonstrar interesse pelo exercício entomológico, Silviano metaforiza-se em borboleta-azul a fim de chamar a intenção do amigo-amado: "Sinto-me uma borboleta-azul a esvoaçar em plena praça Sete. Ele riu." (SANTIAGO, 2014, p. 67).

Para nós, a borboleta-azul corrobora esse voo de liberdade sensível-epistêmico que Silviano aquilata ao escre(vi)ver sua amizade/relacionamento, real e ficcional, com Zeca, sobretudo, de maneira sensível e que (de)marca um estilo de vida gay (ORTEGA, 1999) em 1950 para além das grades históricas abordadas por Ortega. Para Denilson Lopes, em $O$ homem que amava rapažes (2002), "Ser um escritor gay é [...] uma forma de redefinir práticas políticas marcadas pelo cotidiano, uma ética de um sujeito plural e uma estética da existência." (2002, p. 38). A exterioridade, então, dá-se em e a partir de nossos corpos homo-biográficos. Isso posto, o intelectual argentino Walter Mignolo pontua:

Anzaldúa mostra a necessidade uma epistemologia fronteiriça [...] que permita pensar e construir pensamento a partir dos interstícios e que possa aceitar que os [...] homossexuais são categorias fora da lei desde uma epistemologia monotópica que normaliza determinados espaços (nacionais, imperiais), como espaços de contenção e de

\footnotetext{
${ }^{2}$ No romance Mil rosas roubadas, o narrador, lido por nós enquanto o próprio Silviano, escre(vi)ve "[...] tinha escrito que Zeca e eu passamos a falar da transferência de colégio logo depois de eu ter dito que me sentia metamorfoseado em borboleta-azul a esvoaçar nos ares barulhentos e poluidos da praça Sete." (SANTIAGO, 2014, p. 70, grifos nossos). Além disso, ele complementa "Tinha receio de ser incorporado com destaque à diversificada coleção de insetos azuis que o conhecido entomologista amador já tinha alfinetado em papelão na sua casa." (SANTIAGO, 2014, p. 70). Em linhas gerais, as borboletas-azuis foram um importante tema discutido por Silviano e Zeca no primeiro encontro ocorrido na Praça Sete de Setembro em Belo Horizonte. O artista e produtor musical Ezequiel Neves tinha como hobby ir à cata desses insetos e, pelo crivo da admiração latente e pulsante, Silviano se enxergava/sentia como uma borboleta-azul a esvoaçar a Praça Sete à espera do alfinete que o espetaria em papelão de amostragem do colecionador (e amigo-amado Zeca).
} 
marginalização. (MIGNOLO apud NOLASCO, 2015, p. 50, grifos nossos)

Nesse sentido, a partir do contexto da exterioridade o qual nossas reflexões se assentam, entendemos que um dos pontos elementares concernentes ao romance Mil rosas roubadas é substancialmente a óptica da (boa) amizade política, sob a égide de Jacques Derrida e de Francisco Ortega. Mil rosas roubadas (des)arquivam as memórias de Silviano trazendo à baila o que Derrida e Ortega entendem por discurso do epitáfio. Em linhas gerais, o discurso do epitáfio explicita a possibilidade/um compromisso de uma amizade e um amor para além da morte e da vida (ORTEGA, 2009, p. 69). Nesse contexto, o amigo é cópia/imagem de mim assinando uma oração fúnebre (ORTEGA, 2009, p. 69). Assim sendo, Derrida pontua:

Não poderei amar por amizade sem me comprometer, sem antecipadamente me sentir comprometido a amar o outro para além da morte. Logo, para além da vida. Sinto-me, e de antemão, antes de todo e qualquer contrato, levado [porté] a amar o outro morto. Sinto-me assim (levado a) [(porte a)] amar, é assim que me sinto (amar). A autologia dá que pensar, como sempre: sinto-me amar, levado a o morto [...] (DERRIDA, 2003, p. 26, grifos do autor)

Como explicitado, a declaração que abre as portas da narrativa das Mil rosas roubadas pode ser entendida, em menor ou maior grau, como uma espécie de oração fúnebre em relação à morte do amigo-amado Zeca. Sumariamente, a perda, a morte e a tentativa de lidar com a falta de um ente querido delineiam o (des)arquivamento memorialístico de Silviano no romance aposto. Constitui-se, portanto, uma amizade para além da vida a qual, $a$ priori, a ausência se torna presença subsidiada pelo discurso ficcional de Silviano e, agora, pelo epistêmico ensejado por nós enquanto críticos biográficos fronteiriços.

Para Jacques Derrida em Políticas da amizade (2003), "[...] é preciso partir do amigoamante e não e não do amigo-amado para pensar a amizade." (DERRIDA, 2003, p. 23). É crivado na óptica do amigo-amado que Silviano narra sua história com Ezequiel Neves afirmando de modo derridiano a possibilidade de Mil rosas roubadas projetar-se enquanto um romance, essencialmente, sobre a amizade, mas, também, acerca das sociabilidades homo-biográficas, das reflexões relacionadas ao ato de biografar e, dentre outras, do 
trabalho de luto daquele que sobrevive à morte do amado. Há uma tentativa de lidar com a sombra fantasmagórica da morte (real/ficcional) alicerçada pelo discurso literário-epistêmico de uma ficção teórica. Valendo-se da memória faltosa, lacunar e falha, Silviano supre essas faltas ficcionalmente a fim de narrar sua escrita-vivência homo-biográfica com Zeca a partir de sua (boa) amizade política. Por esse tipo de relação, entendemos:

A boa amizade supõe a desproporção. Exige uma certa ruptura de reciprocidade ou de igualdade [...] A boa amizade nasce da desproporção quando se estima ou respeita (acbtet) o outro mais do que a si mesmo - e eis aqui uma segunda partilha, na amância, entre a amizade e o amor. A boa amizade supõe, claro, um certo ar, um certo toque (Anstrich) de intimidade, mas uma intimidade sem intimidade propriamente dita. (DERRIDA, 2003, p. 74)

Silviano e Zeca são amigos políticos na medida em que não reproduzem um modelo fraternal de amizade, eles não apenas (re)afirmavam suas subjetividades um pelo outro, mas, politicamente, pelas personalidades e comportamentos extremamente opostos. Os amigos, por sua vez, transformavam-se pelos confrontos, pelos atritos ou, pelo que o próprio romance expõe, através dos desentendimentos passageiros e profundos (SANTIAGO, 2014, p. 215) estabelecendo o que os intelectuais da amizade supracitados entendem como o processo de ascese (DERRIDA, 2003) (ORTEGA, 2009).

A amizade, nesse prisma, representa um apelo a novas formas de experimentações de sociabilidades, um exercício do político, uma busca por alternativas alheias às normas tradicionais de relacionamentos. Silviano e Zeca explicitam escolhas de vida extremamente distintas, ficcional e biograficamente, visto que aquele, enquanto crítico e professor, opta por seguir a carreira acadêmica, dedicar-se à aposentadoria e à calmaria de uma vida comum, já Ezequiel escolhe experienciar os paraísos artificiais dos anos 1950, debruçar-se sobre as boêmias do mundo e, de maneira descortinada, levar a vida na posição de um artista sem grandes preocupações institucionais. Silviano e Zeca co-habitam lados distintos de uma mesma moeda homo-biográfica em que suas aproximações político-afetivas são crivadas na diferença.

Ainda no que convém ao plano da diferença entre os amigos-amantes, julgamos necessário pontuar, conforme a ideia de se aproximar pela semelhança na diferença, que os 
amigos possuíam personalidades opostas e que em demasiados momentos confrontavamse não desestruturando, com isso, a amizade que, se alocada em uma perspectiva fraternalista e não transformadora, pudesse entrar em ruínas. O modo de sociabilidade político e homo-biográfico que Silviano e Zeca promoviam nos leva a compreender que a discórdia não deve ser considerada como algo que desestabilize uma relação, mas que a fortaleça. Silviano afirma:

Demonstrava coragem suficiente para afirmar - diante de possível e inconveniente ruptura na amizade - que a discórdia entre amigos não deve ser considerada como algo de estranho à expansão infinita dos sentimentos fraternos. Aliás, acrescentava, que no terreno apimentado pelos afetos, há sempre que abrir espaço para os desentendimentos passageiros e profundos. (SANTIAGO, 2014, p. 215)

Sob a pluma de todas as reflexões homo-biográficas apostas, endossamos, portanto, que a exterioridade se apresenta como um lugar criado e posto em nós, em nossos corposfronteiras, em nossos loci, em nossas reflexões epistêmicas e, sobretudo, em nossos projetos homo-bio-ficcionais. Silviano e Virginia pensam, produzem e escre(vi)vem a partir de uma consciência existencial outra que se aquilata em escritas-vivências de homens e mulheres homo-biográficos erigindo produções à luz de suas sensibilidades e de seus próprios corpos outros tal qual realizamos enquanto críticos comparatistas biográficos fronteiriços que pensam, sentem e falam a partir de um lugar outro, subalterno e marginalizado. Somos, então, uns-nos-outros homo-biograficamente por intermédio da literatura. No plano dessa exterioridade tomada pelas questões invocadas por Orlando, Silviano assente:

Sem dúvida, Orlando: Uma biografia causará ainda rebuliço nestes anos em que a sociedade é julgada permissiva pelos conservadores e os costumes se beneficiam da tolerância que só é invocada pelos bempensantes nos momentos de crise. O romance de Virginia Woolf convida o leitor a evitar o vocabulário 'tolerância'. Este resguarda a ideia de desigualdade sob a forma de generosidade do privilegiado. A institucionalização dos direitos libertários e civis deve acentuar não a tolerância, mas a pluralidade - de que o romance é exemplo maior. Pensar, por exemplo, que o corpo de Orlando se monta e se reinventa a cada dia, a cada ano, a cada século, como a série de esculturas Bichos, de Lygia Clark. No contato com as mãos do mundo, Orlando, o romance, se monta e se reinventa por um delicado e sutil sistema de dobradiças, que guardam as possibilidades infinitas do 
jogo entre a flexibilidade e o rigor. (SANTIAGO, 2017, p. 284, grifos do autor)

Por isso, entendemos que as escritas-vivências de Silviano e Virginia, além das nossas, aproximam-se e distanciam-se, uma vez que escrevi(ve)mos a partir de experiências e de sensibilidades biolocais específicas dos nossos próprios corpos políticos perpassados por homo-bios diversais. Mil rosas roubadas e Orlando, enquanto textos que (des)arquivam memórias outras sobre/a partir da perda de um amigo-amor-político e o esfacelamento de uma relação de amor, escre(vi)vem-se marcadamente a partir desse lugar outro (do Fora) não contemplado nem politicamente pelos padrões modernos, coloniais e patriarcais, nem pelas formas de existências, experiências e sociabilidades políticas construídas culturalmente fraternas e não transformadoras. Ortega, nesse sentido, corrobora:

Ao passo que a amizade foi aceita social e culturalmente, a homossexualidade não representava problema, mas, desde que amizade se desfaz como forma de relação tolerada culturalmente, a seguinte pergunta torna-se atual: "Que fazem os homens juntos?”. A homossexualidade torna-se um problema médico e sociopolítico. [...] A amizade tem, para Foucault, principalmente o sentido de uma amizade homossexual. Sua atenção concentra-se, principalmente, nas possibilidades disponíveis hoje na cultura homossexual para criar novas formas de amizade. (ORTEGA, 1999, p. 165)

No plano dessa cultura homossexual para fomentar novas formas de amizade é onde se situa, também, a amizade/relacionamento amoroso de Virginia e Vita (Figura 4). Para o crítico Tomaz Tadeu, elas não podiam ser mais diferentes (TADEU, 2017, p. 229), haja vista que possuíam modos de vidas, de existências e personalidades estritamente distintas. Virginia compunha a classe média intelectualizada inglesa, enquanto Vita era herdeira da nobreza britânica Sackville-West. A vida sexual de Virginia era recatada e se suspeita de não ter sido consumada no casamento com Leonardo. Vita, pelo contrário, tinha uma vida sexual intensa, permeada por homens e mulheres, além de ter se casado com Harold, um diplomata de inclinações homossexuais (TADEU, 2017, p. 229). 
Figura 4 - Virginia Woolf (à esquerda), Vita Sackville-West (à direita) e seus cachorros os quais eram um amor em comum para ambas as mulheres e escritoras inglesas

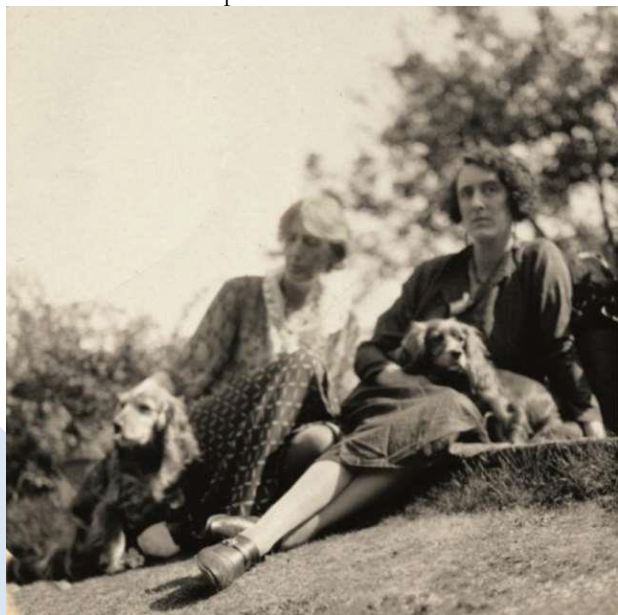

Fonte: http://www.blogletras.com/2016/09/amo-como-mulher-e-e-te-amo-por-que-es.html

Assim sendo, encaminhamo-nos para o fim de nossas postulações críticas desnudadas ressaltando que evocamos as diferenças entre Virginia e Vita com o intuito de aproximálas, a partir do que mais as difere, ao relacionamento político-enamorado de Silviano e Zeca em Mil rosas roubadas. Ambos os casais, aos seus modos, épocas e loci, experienciaram modos de vidas outros possibilitados pelas convivialidades políticas endossadas pela amizade. Nesse ínterim, é pelo que mais diferiam-se que os amigos-amantes, tanto os brasileiros quanto as inglesas, aproximavam-se. Metaforicamente, concluímos nossas articulações comparatistabiográficas entrevendo que no meio do caminho das nossas comparações havia um/uma jovem chamado/a Orlando roubando, justamente, rosas fúnebres do que restou dos amores homo-biográficos não só de Virginia Woolf, entremeada por Vita Sackville-West, mas, sobremaneira, de Silviano Santiago atravessado pelo amor e pela amizade compartilhados com Ezequiel Neves. 


\title{
THE MEMORIALISTIC DENUDES OF THE HOMO-BIOS OF SILVIANO SANTIAGO AND VIRGINIA WOOLF
}

\begin{abstract}
This work aims to make a comparative, biographical and border reading between the works Mil rosas roubadas (2014) by Brazilian writer Silviano Santiago and Orlando: uma biografia (2017) by the English Virginia Woolf. For this purpose, we will use a bibliographic methodology based on the border biographical critical epistemology in order to discuss the homo-biographical similarities and differences between the authors and the books cited while, simultaneously, promoting denudes of their literary, metaphorical and empirical personae traversed by the (auto)biographical spaces that cornice them. Among the concepts used for the mentioned opportunity, we will use memory, aliados bospitaleiros, exteriority, homo-biography and friendship corroborated, among others, by the intellectuals Leonor Arfuch, Eneida Maria de Souza, Juliano Garcia Pessanha, Walter Mignolo, Jacques Derrida and Francisco Ortega. Therefore, supported by the foregoing, we will seek to outline comparative spellings between Silviano and Virginia with regard to their other existences while homosexual writers who escre(vi)vem, or escre(vi)veram, settling in modus operandi and vivendi that can bring them not only closer in terms of their homo-biographical and literary similarities, but, above all, of the differences that separate them by bringing them closer together.
\end{abstract}

KEYWORDS: Critical biographical frontier; Silviano Santiago; Virginia Woolf; Homo-biographies; Desnudar.

\section{REFERÊNCIAS}

ARFUCH, Leonor. O espaço biográfico: dilemas da subjetividade contemporânea. Tradução de Paloma Vidal. Rio de Janeiro: Editora UERJ, 2010.

CURTIS, Vanessa. As mulheres de Virginia Woolf. Tradução de Tuca Magalhães. São Paulo: A Girafa Editora, 2005.

DERRIDA, Jacques. Políticas da amizade: seguido de o ouvido de Heidegger. Porto: Campo das Letras, 2003.

EVARISTO, Conceição. Becos da memória. Rio de Janeiro: Pallas, 2017.

FONSECA, Maria Nazareth Soares. Posfácio: costurando uma colcha de memórias. In: EVARISTO, Conceição. Becos da memória. Rio de Janeiro: Pallas, 2017, p. 191-198.

LOPES, Denilson. O homem que amava rapazes: e outros ensaios. Rio de Janeiro: Aeroplano, 2002.

NOLASCO, Edgar Cézar. Crítica biográfica fronteiriça (Brasil/Paraguai/Bolívia). CADERNOS DE ESTUDOS CULTURAIS: Brasil/Paraguai/Bolívia, Campo Grande: UFMS, v. 7, n. 14, p. 47-63, jul./dez. 2015.

ORTEGA, Francisco. Genealogias da amizade. São Paulo: Editora Iluminuras, 2002. 
ORTEGA, Francisco. Amizade e estética da existência em Foucault. Rio de Janeiro: Editora Graal, 1999.

. Para uma política da amizade: Arendt, Derrida, Foucault. Rio de Janeiro: Relume Dumará, 2009.

PESSANHA, Juliano Garcia. Recusa do não-lugar. São Paulo: Editora UBU, 2018.

SANTIAGO, Silviano. Mil rosas roubadas. São Paulo: Companhia das Letras, 2014.

. Entre a flexibilidade e o rigor. In: WOOLF, Virginia. Orlando. Tradução de Tomaz Tadeu. Belo Horizonte: Autêntica Editora, 2017, p. 265-284.

SCHULKIND, Jeanne. Introdução. In: WOOLF, Virginia. Momentos de vida. Tradução de Paula Maria Rosas. Rio de Janeiro: Nova Fronteira, 1986, p. 15-30.

SOUZA, Eneida Maria de. Janelas indiscretas: ensaios de crítica biográfica. Belo Horizonte: Editora UFMG, 2011.

. Tempo de pós-crítica: ensaios. Veredas \& Cenários, 2012.

TADEU, Tomaz. Notas. In: WOOLF, Virginia. Orlando. Tradução de Tomaz Tadeu.

Belo Horizonte: Autêntica Editora, 2017, p. 219-259.

WOOLF, Virginia. Orlando. Tradução de Tomaz Tadeu. Belo Horizonte: Autêntica Editora, 2017.

Recebido em: 21/09/2020.

Aprovado em: 17/01/2021. 